\title{
Herpes zoster vaccination in the elderly subjects: improving awareness and uptake
}

This article was published in the following Dove Press journal:

Patient Intelligence

6 October 2015

Number of times this article has been viewed

\section{Armando Stefanati \\ Nicoletta Valente \\ Silvia Lupi \\ Sara Previato \\ Matilde Giordani \\ Giovanni Gabutti}

Department of Medical Sciences, University of Ferrara, Ferrara, Italy
Correspondence: Giovanni Gabutti Department of Medical Sciences, University of Ferrara, via Fossato di Mortara 64B, 44I2I Ferrara, Italy $\mathrm{Tel}+390532455568$ Fax +390532 205066 Email giovanni.gabutti@unife.it
Abstract: Herpes zoster (HZ) is a common disease in adults and older subjects solely related to the reactivation of latent varicella zoster virus in ganglia. The incidence of the disease increases with aging and the decline of varicella zoster virus-specific cell-mediated immunity. $\mathrm{HZ}$ has a significant impact on the quality of life of subjects during the acute phase. Besides, pain can persist even for a long time becoming chronic. The chronic pain following $\mathrm{HZ}$ is called postherpetic neuralgia, and it is a debilitating long-lasting condition, characterized by metameric pain, allodynia, and hyperalgesia. Therapeutic options against $\mathrm{HZ}$ and postherpetic neuralgia are often suboptimal and the impact of the disease and its complications on daily living activities is significant, especially in older subjects. Nowadays, a preventive approach to the disease is possible; as a matter of fact, a high-antigen content live vaccine is available. This vaccine has a good profile in terms of immunogenicity, efficacy, effectiveness, and safety and its use may prevent both $\mathrm{HZ}$ and postherpetic neuralgia. Nevertheless, the evaluation of the issues raised in countries that introduced this immunization show that both provider and patient barriers could have prevented a more robust uptake of HZ vaccination. In the USA, HZ immunization storage was expensive, reimbursement was cumbersome, and supply shortages may have limited promotion by the interests of the manufacturer and provider. The doctors did not actively recommend $\mathrm{HZ}$ vaccination; on the other hand, subjects were mostly unaware of the $\mathrm{HZ}$ vaccine. Several demographic factors, including sex and educational level, could have negatively affected the coverage rates; besides, the clinicians who treat adults focus less on vaccination than those taking care of children. On the other hand, when health care professionals undertook every effort to maximize the uptake of the shingles vaccine (eg, in the UK), the vaccine coverage rate increased very quickly.

Keywords: herpes zoster, postherpetic neuralgia, vaccine

\section{Epidemiological background}

Herpes zoster (HZ) is an infectious disease caused by the varicella zoster virus (VZV), a herpesvirus mainly acquired during childhood. VZV is transmitted through air droplets and/or direct contact with skin lesions of subjects affected by varicella or HZ. ${ }^{1}$ The reservoir is exclusively human and VZV typically shows an endemic-epidemic trend. ${ }^{2}$ The primary infection, called varicella (chickenpox), is highly contagious and elicits a VZV-specific humoral and cell-mediated immunity. ${ }^{3}$ During primary infection, VZV reaches sensory ganglia where it establishes a lifetime immune-controlled latent infection. The incidence of HZ is closely linked to a VZV-specific cell-mediated immunity decrease, which is strictly related with aging. ${ }^{4}$ Some chronic diseases seem related to an increase of $\mathrm{HZ}$ incidence (eg, chronic obstructive pulmonary disease, diabetes).$^{5}$ Viral reactivation in sensory ganglia implies neuronal necrosis, intense inflammation, 
and neuritis; then, the virus causes the typical rash with a dermatomeric distribution. The characteristic cluster of vesicles is accompanied by radicular pain that usually disappears in 1-2 months. ${ }^{6}$ The HZ-associated pain can become chronic persisting for several months after the eruption. This condition is defined as postherpetic neuralgia (PHN). ${ }^{7}$ The estimated risk of developing $\mathrm{HZ}$ during a lifetime is strictly age-related; as a whole it is equal to $10 \%-30 \%$, but can increase up to $50 \%$ in $>85$-year-old subjects. HZ onset can also be related to sex, seasonality, race, psychological stress, mechanical trauma, immunotoxic chemicals, and genetic predisposition. ${ }^{8}$

$\mathrm{HZ}$ incidence is quite similar all over the world; the disease does not show a seasonal or epidemic trend and its incidence is not related to varicella epidemic outbreaks. Aging is a relevant risk factor; as a matter of fact, at least $25 \%$ of subjects will develop HZ during life and most cases ( $75 \%$ ) occur in people older than 50 years. ${ }^{9}$ The worldwide estimates of incidence range between two to three cases per 1,000 person-years in the 20-50 years age group and six to seven cases per 1,000 person-years in $>70$-year-old subjects. The impact of $\mathrm{HZ}$ on the quality of life is significant, particularly in older people. ${ }^{10}$ Taking into account that $\mathrm{HZ}$ incidence grows markedly with age $^{11}$ and that the number of older people is increasing all over the world, particularly in industrialized countries, a greater impact of $\mathrm{HZ}$ can be estimated. ${ }^{12}$ Recurrence rate in immunocompetent is usually low $(4 \%-5 \%)$, probably because a single episode of $\mathrm{HZ}$ results in a very strong boost in VZV-specific cell-mediated immunity. ${ }^{13}$ Recurrences are significantly more likely in subjects with HZ-associated pain of 30 days or longer at the initial episode (hazard ratio, 2.80; 95\% confidence interval, $1.84-4.27 ; P<0.001)$ and in immunocompromised individuals (hazard ratio, 2.35; $95 \%$ confidence interval, 1.35-4.08; $P=0.006)$. Subjects aged 50 years or older at the index episode also have a greater likelihood of recurrence. ${ }^{14}$

Complications can occur in $13 \%-40 \%$ of cases $^{15}$ and chronic pain is the most relevant. ${ }^{16} \mathrm{PHN}$ estimated incidence ranges between $10 \%$ and $20 \%$ of cases of $\mathrm{HZ}$ (reaching $30 \%$ in older subjects). ${ }^{17}$ Most PHN cases (up to $80 \%$ ) occur in $>50$-year-old subjects. ${ }^{18}$

\section{Clinical aspects}

$\mathrm{HZ}$ is characterized by a vesicular rash and pain with dermatomal distribution. ${ }^{19}$ A prodromal aspecific phase can occur $1-5$ days before the onset of the rash $(70 \%-80 \%$ of cases $) .{ }^{20}$ During the acute phase of the disease, the VZV infects the cells of the dermis and epidermis and causes a typical rash, usually affecting a single dermatome. ${ }^{13}$
Thoracic and lumbar dermatomes (from T1 to L2) are mostly involved as well as the first branch of the trigeminal nerve; however, subjects can develop lesions in adjacent dermatomes also. ${ }^{21}$

The patient is contagious during the vesicular phase and can spread the virus to susceptible subjects causing chickenpox. Rash is usually accompanied by a dermatomal, mild to severe, pain syndrome. ${ }^{22}$ The acute phase can be followed by a chronic one, represented by PHN, characterized by a pain that continues even after the rash healing. Risk factors for $\mathrm{PHN}$ are old age $(>50$ years), as well as the acute pain and of the rash severity. ${ }^{23} \mathrm{PHN}$ is the most common complication of HZ. The patient affected by PHN reports different types of pain: constant, intermittent, or following stimuli that are not normally painful (allodynia). PHN interferes with basic activities of daily living and is usually defined as a long-term chronic HZ-related pain persisting at least 3 months after the acute phase. Other complications, although less frequent, in elderly or immunocompromised subjects, are disseminated HZ, ocular inflammation, ${ }^{24}$ stroke, ${ }^{25}$ focal motor paralysis, and Ramsay Hunt syndrome. ${ }^{26}$

\section{Impact of $\mathbf{H Z}$ on quality of life}

The World Health Organization defines health as "a state of complete physical, mental and social well-being, not simply defined by the absence of disease or infirmity". ${ }^{27}$ The term quality of life describes the overall sense of well-being that a person is living, and how well that person can live a normal life. Quality of life items include basic activities (for example, management of bathing, dressing, and eating), complex tasks (such as grocery shopping or doing household chores), and emotional well-being (level of fear, anxiety, stress, and concentration). $\mathrm{HZ}$ is extremely debilitating. In addition to the typical symptoms of skin lesions and associated pain, subjects suffer an impaired ability to perform common daily activities or to maintain social and familiar relationships. PHN pain influences the performance in relation to the general living (in $40 \%$ of cases) and leisure activities (in $48 \%$ of cases) ${ }^{28}$ The onset of typical symptoms of skin lesions and pain associated with the functional and social issues can induce, in case of relapse, an alteration of the psychological state of the subject. Subjects with intense pain are at an increased risk of anxiety and depression than those who claim a mild pain.

\section{Diagnosis and therapeutic options}

Diagnosis of HZ is usually based on anamnesis and physical examination. However, the vesicular eruption may be atypical, especially in immunocompromised individuals. The detection of virus is possible by a polymerase chain reaction 
or by isolating the VZV in culture from vesicular fluid, crusting, cerebrospinal fluid, or other samples. Isolation of VZV from lesions, however, is difficult and the growth of the virus requires several days (from 3 to 14 days). Direct immunofluorescence is used for quick response even if the test has a lower sensitivity than the polymerase chain reaction. ${ }^{29}$

Serological methods may also be used for laboratory diagnosis, although there are challenges in interpreting the results. Subjects with $\mathrm{HZ}$ may mount an immunoglobulin $\mathrm{M}$ (IgM) response and would be expected to mount a memory immunoglobulin $\mathrm{G}$ ( $\mathrm{IgG}$ ) response. However, a positive IgM enzyme linked immunosorbent assay result could be an indication of primary VZV infection, reinfection, or reactivation. It is also difficult to detect an increase in IgG in the laboratory diagnosis of $\mathrm{HZ}$ since subjects may have a high baseline antibody titer deriving from previous varicella disease. ${ }^{30}$

The therapeutic approach to HZ mainly addresses the recovery of the eruption, relief of pain, and reduction of complications. ${ }^{31}$ However, the available antiviral (such as aciclovir, famciclovir, and valaciclovir), anti-inflammatory, and analgesic drugs are only partially effective in limiting the acute disease and do not reliably alter the course of PHN. ${ }^{32}$

Noteworthy, antiviral therapy should be started within 72 hours after the appearance of the rash, but often a delay in seeking doctor's advice occurs.

Oral antiviral agents are recommended for 7 days in subjects at risk of developing PHN, but the pharmacological and preventive options against PHN are frequently suboptimal. ${ }^{33}$

\section{Vaccine and immunization}

The rationale for the development of a preventive approach against $\mathrm{HZ}$ is based on its epidemiological impact, complications, and the related costs. Noteworthy, it is demonstrated that the vaccines for chickenpox with high antigenic content elicit a significant increase in VZV-specific cell-mediated immunity. ${ }^{34}$ Now, a vaccine against $\mathrm{HZ}$ has been licensed. It contains a live, attenuated cell-free preparation of the Oka strain of VZV used for pediatric varicella immunization, but the antigen content is at least 14 times higher than the chickenpox vaccine used in childhood. ${ }^{35}$ This vaccine was first approved by the US Food and Drug Administration for use in subjects over 60 years of age, in 2006, and subsequently (in 2011) also in adults over 50 years of age. ${ }^{36}$

In Europe, the authorization was granted for subjects over 60 years of age in May 2006 and from 2007 for the immunization of individuals of 50 years of age or older. The vaccine should be administered subcutaneously as a single dose of $0.65 \mathrm{~mL}$.
The clinical efficacy has been evaluated in two large Phase III studies involving subjects $>60$ years old (Shingles Prevention Study [SPS]), ${ }^{37}$ and 50-59-year-old subjects (Zoster Efficacy and Safety Trial [ZEST]), ${ }^{38}$ respectively. The SPS study showed a reduction in the incidence of shingles $(51.3 \%)$, PHN (66.5\%), and burden of illness (a severity-by-duration measure representing the total HZassociated pain and discomfort in a population of study subjects; $61.1 \%$ ), as well as an excellent safety and tolerability profile. $^{39}$

The ZEST study showed an efficacy of $69.8 \%$ in the prevention of HZ in subjects aged $50-59$ years. ${ }^{40}$ The persistence of the duration of protection against $\mathrm{HZ}$ and $\mathrm{PHN}$ has been evaluated in a short-term study showing an efficacy equal to $39.6 \%$ and $60.1 \%$ for the prevention of $\mathrm{HZ}$ and of PHN, respectively. ${ }^{41}$

A long-term study, extending the follow-up to 12 years after vaccination, estimated a vaccine efficacy equal to $21 \%$ for $\mathrm{HZ}$ and $35 \%$ for the incidence of PHN in over 70-yearold subjects. ${ }^{42}$

Other studies confirmed the profile of effectiveness and the level of protection against $\mathrm{HZ}$ and PHN. ${ }^{43,44}$

The SPS and ZEST studies allowed evaluation of the safety and tolerability of the zoster vaccine and showed this vaccine is generally well tolerated. The frequency of serious adverse events, systemic adverse events, and hospitalizations was low and the vaccine did not cause or induce HZ, not even in the weeks immediately following vaccination. Overall, the most commonly reported side effects (occurring in at least 1 in 10 individuals) were reactions at the injection site (redness, swelling, pain, and itching) and headache (occurring in at least 1 in 100 and less than 1 in 10 individuals); the rate of $\mathrm{HZ}$ form or varicella-like rashes not localized in the injection site within 42 days post-vaccination was similar in the group of vaccinated subjects and the placebo group and no cases of secondary transmission of the vaccine virus were reported. ${ }^{45}$

\section{Use, indications, and contraindications}

The live attenuated virus vaccine is indicated for the prevention of $\mathrm{HZ}$ and $\mathrm{PHN}$ in subjects who are 50 years old and over.

The vaccine is available in the form of powder and solvent for dissolving in a solution for injectable suspension and is administered subcutaneously as a single dose of $0.65 \mathrm{~mL}$ in the deltoid region of the arm. ${ }^{46}$

It requires caution in the chain of distribution as it should be stored and transported refrigerated between $2^{\circ} \mathrm{C}$ and $8^{\circ} \mathrm{C}$ in order to guarantee stability. ${ }^{47}$ 
An intramuscular administration does not involve any problem in terms of safety and efficacy. The vaccine can be administered to VZV-naïve subjects as well as to subjects with positive history for $\mathrm{HZ}$ and can be co-administered (separate injections in different parts of the body) with the inactivated influenza vaccine, but not with the 23 -valent pneumococcal vaccine.

Contraindications include history for hypersensitivity to any component of the vaccine, even in trace amounts (eg, neomycin), primary and acquired immunodeficiency (for acute and chronic leukemia; lymphoma or other conditions involving bone marrow or lymphatic system; immunosuppression for human immunodeficiency virus/acquired immunodeficiency syndrome; impairment of cellular immunity), immunosuppressive therapy (including high dose corticosteroids), untreated active tuberculosis, and pregnancy. Vaccination is not contraindicated in subjects who are receiving topical or low dose corticosteroids or glucocorticoids or in subjects who are receiving corticosteroids as replacement therapy. ${ }^{47}$

\section{Importance of awareness and uptake}

In the USA, the vaccine has been recommended since 2006 , but official recommendations that may have impacted on physicians' vaccination behavior were published in June 2008. Immediately after the availability of the vaccine, the coverage rate among adults recommended to receive the $\mathrm{HZ}$ vaccine was low: just $1.9 \%$ among subjects aged $>60$ years in 2007 and $6.7 \%$ in 2008 .

Lu et al examined $\mathrm{HZ}$ vaccination coverage in subjects aged $>60$ years in the USA and evaluated factors affecting the uptake of $\mathrm{HZ}$ vaccine in this population. ${ }^{48}$

They concluded that, probably, both provider and patient barriers could have prevented a more robust uptake of $\mathrm{HZ}$ vaccination. It appeared that $\mathrm{HZ}$ vaccination stocking was expensive because of stringent storage and handling requirements, reimbursement through Medicare was cumbersome, and supply shortages may have limited promotion by the manufacturer and provider. The study suggested that doctors did not actively recommend $\mathrm{HZ}$ vaccination (over three quarters of subjects would have accepted the vaccination if their doctors recommended it); on the other hand, subjects were mostly unaware of the $\mathrm{HZ}$ vaccine and for this reason did not seek advice about it from their physician.

Besides, several demographic factors, including sex and educational level, could have negatively affected the coverage rates, even though the impact of these issues is hard to assess given the low overall vaccination coverage. Probably, only age was a strong predictor of $\mathrm{HZ}$ vaccination, with subjects aged $\geq 75$ years approximately three times more likely to receive $\mathrm{HZ}$ vaccine than those aged 60-74 years. Perhaps the difference may be due to more frequent medical encounters by older adults. ${ }^{49}$

Other studies suggested that clinicians serving adults focus less on vaccination than those serving children, apparently because adults tend to present with acute clinical needs whereas vaccination and well-patient care are emphasized and constitute a larger portion of pediatric practice. ${ }^{50}$

In Europe, vaccination is recommended and/or reimbursed in Austria (since 2007); UK, Germany, and Sweden (since 2010); Greece (since 2011); France (since 2013); and Italy (since 2014).

In the UK in 2013, following recommendation by the Joint Committee on Vaccine and Immunization, immunization started, involving two cohorts of subjects, 70- and 79 -year-olds. Every effort has been made by health care professionals to maximize the uptake of the shingles vaccine and after only one year, the vaccine coverage rate reached $61.8 \%$ in those aged 70 years and $59.6 \%$ in those aged 79 years. ${ }^{51}$

After the UK, France was the second European country to decide to offer national vaccination to seniors from June 2015 , reimbursing the vaccine for a cohort of people aged 65-74 years. ${ }^{52}$ In Italy from 2015, three regions (Liguria, Sicily, and Calabria) recommend and fund the vaccination, mainly through an age-based strategy for seniors.

\section{Discussion and conclusion}

$\mathrm{HZ}$ is a very common disease associated with severe complications and a negative impact on quality of life. Early diagnosis is sometimes missed and therapeutic approach is often suboptimal. Besides, complications can occur, PHN being the most common and debilitating one. As the rate of frail and elderly people is progressively increasing, a growing impact of $\mathrm{HZ}$ and its complication can be estimated. For all these reasons, prevention is essential. Nowadays, thanks to the availability of an effective, safe and well-tolerated vaccine, there is a great opportunity to achieve a positive impact on the health of vulnerable elderly people helping to provide a healthy aging, free from $\mathrm{HZ}$ and its complications. Even though the vaccine turned out to effectively reduce the incidence and the severity of $\mathrm{HZ}$, its uptake remains low. The reasons for this low coverage rate are several. One of the major issues is the low awareness about the need of immunization in adults among the general population. Moreover, adult/elderly subjects largely rely on health care provider 
recommendations for immunization. ${ }^{53}$ To overcome this problem, the Community Preventive Services Task Force and the National Vaccine Advisory Committee in the USA have recently endorsed health care workers to promote, recommend, and offer immunization at every clinical visit. ${ }^{54}$ Noteworthy, the above-mentioned issues are not the only reasons for the low uptake of the vaccine; as a matter of fact, the costs and shortages of the vaccine play a relevant role in lowering the coverage rate, at least in some countries. ${ }^{54}$

Recently published studies confirmed the crucial role played by any health care provider in promoting this immunization and suggested the opportunity to involve not only physicians or nurses but also pharmacists in the counseling and promotion of immunization. ${ }^{55}$

In conclusion, every effort should be made in order to remove barriers and increase the knowledge of and compliance with this immunization.

\section{Disclosure}

GG received grants from GlaxoSmithKline Biologicals SA, Sanofi Pasteur MSD, Novartis, Crucell/Janssen, and Pfizer for taking part in the advisory board and expert meetings, for being a speaker or an organizer of congresses/conferences, and for acting as an investigator in clinical trials. The other authors AS, NV, SL, $\mathrm{SP}$, and MG report no conflicts of interest in this work.

\section{References}

1. Paek E, Johnson R. Public awareness and knowledge of herpes zoster: results of a global survey. Gerontology. 2010;56:20-31.

2. Harpaz R, Ortega-Sanchez IR, Seward JF; Advisory Committee on Immunization Practices (ACIP) Centers for Disease Control and Prevention (CDC). Prevention of herpes zoster: recommendations of the Advisory Committee on Immunization Practices (ACIP). MMWR Recomm Rep. 2008;57(RR-5):1-30.

3. Heininger U, Seward JF. Varicella. Lancet. 2006;368:1365-1376.

4. Weaver BA. Herpes zoster overview: natural history and incidence. J Am Osteopath Assoc. 2009;109(S2):S2-S6.

5. Okamoto S, Hata A, Sadaoka K, Yamanishi K, Mori Y. Comparison of varicella-zoster virus specific immunity of patients with diabetes mellitus and healthy individuals. J Infect Dis. 2009;200:1606-1610.

6. Johnson RW. Herpes zoster and postherpetic neuralgia. Expert Rev Vaccines. 2010;9:21-26.

7. Thyregod HG, Rowbotham MC, Peters M, Possehn J, Berro M, Petersen KL. Natural history of pain following herpes zoster. Pain. 2007;128:148-156.

8. Thomas SL, Hall AJ. What does epidemiology tell us about risk factors for herpes zoster? Lancet Infect Dis. 2004;4:26-33.

9. Lee VK, Simpkins L: Herpes zoster and postherpetic neuralgia in the elderly. Geriatr Nurs. 2000;21:132-136.

10. Gross G, Schöfer H, Wassilew S, et al. Herpes zoster guideline of the German Dermatology Society (DDG). J Clin Virol. 2003;26(3): 277-289.

11. Yawn BP, Saddier P, Wollan PC, St Sauver JL, Kurland MJ, Sy LS A population-based study of the incidence and complication rates of herpes zoster before zoster vaccine introduction. Mayo Clin Proc. 2007;82(11):1341-1349.
12. Whitley RJ, Volpi A, McKendrick M, Wijck Av, Oaklander AL. Management of herpes zoster and post-herpetic neuralgia now and in the future. J Clin Virol. 2010;48(Suppl 1):S20-S28.

13. Johnson RW, McElhaney J, Pedalino B, Levin M. Prevention of herpes zoster and its painful and debilitating complications. Int J Infect Dis. 2007;11(Suppl 2):S43-S48.

14. Yawn BP, Wollan PC, Kurland MJ, St Sauver JL, Saddier P. Herpes zoster recurrences more frequent than previously reported. Mayo Clin Proc. 2011;86(2):88-93.

15. Drolet M, Oxman MN, Levin MJ, et.al. Vaccination against herpes zoster in developed countries. Hum Vaccin Immunother. 2013;9(5): 1177-1184.

16. Jeon YH. Herpes Zoster and Postherpetic Neuralgia: practical consideration for prevention and treatment. Korean J Pain. 2015;28(3):177-184.

17. Nalamachu S, Morley-Forster P. Diagnosing and managing postherpetic neuralgia. Drugs Aging. 2012;29:863-869.

18. Yawn BP, Gilden D. The global epidemiology of herpes zoster Neurology. 2013;81(10):928-930.

19. Janninger CK, Eastern JS, Hospenthal DR, Moon JE. Herpes zoster. Emedicine. 2013; Medscape reference number 1132465.

20. Gnann JW Jr, Whitley RJ. Clinical practice: herpes zoster. $N$ Engl J Med. 2002;347:340-346.

21. Meister W, Neiss A, Gross G, et al. Demography, symptomatology, and course of disease in ambulatory zoster patients. A physician-based survey in Germany. Intervirology. 1998;41:272-277.

22. Haanpää M, Laippala P, Nurmikko T. Pain and somatosensory dysfunction in acute herpes zoster. Clin J Pain. 1999;15:78-84.

23. Ropper AH, Samuels MA. Viral infections of the nervous system, chronic meningitis, and prion diseases. In: Adams and Victor's Principles of Neurology. 9th ed. New York: McGraw-Hill, Inc.; 2009:711-745.

24. Opstelten W, Zaal MJ. Managing ophthalmic herpes zoster in primary care. BMJ. 2005;331:147-151.

25. Kang JH, Ho JD, Chen YH, Lin HC. Increased risk of stroke after a herpes zoster attack: a population-based follow-up study. Stroke. 2009;40(11):3443-3448.

26. Wagner G, Klinge H, Sachse MM. Ramsay Hunt syndrome. J Dtsch Dermatol Ges. 2012;10(4):238-244.

27. WHO. Preamble to the Constitution of the World Health Organization as adopted by the International Health Conference, New York, 19-22 June, 1946, and entered into force on April 7, 1948.

28. Lukas K, Edte A, Bertrand I. The impact of herpes zoster and postherpetic neuralgia on quality of life: patient-reported outcomes in six European countries. Z Gesundh Wiss. 2012;20:441-451.

29. WHO. Varicella and herpes zoster vaccines: WHO position paper, Jun 2014. Wkly Epidemiol Rec. 2014;89(25):265-287.

30. CDC. Shingles (Herpes Zoster): Diagnosis and Testing; May 2014. Available from: http://www.cdc.gov/shingles/hcp/diagnosis-testing html.

31. Galluzzi KE. Management strategies for herpes zoster and postherpetic neuralgia. J Am Osteopath Assoc. 2007;107(Suppl 1):S8-S13.

32. Fashner J, Bell AL. Herpes zoster and postherpetic neuralgia: prevention and management. Am Fam Phys. 2011;83(12):1432-1437.

33. Attal N, Cruccu G, Baron R, et al. EFNS guidelines on the pharmacological treatment of neuropathic pain: 2010 revision. Eur J Neurol. 2010;17:1113-1123.

34. Oxman MN. Immunization to reduce the frequency and severity of Herpes Zoster and its complications. Neurology. 1995;45(12 Suppl 8): S41-S46.

35. Levin MJ, Barber D, Goldblatt E, et al. Use of a live attenuated varicella vaccine to boost varicella-specific immune responses in seropositive people 55 years of age and older: duration of booster effect. $J$ Infect Dis. 1998;178(Suppl 1):S109-S112.

36. Trannoy E, Berger R, Holländer G, et al. Vaccination of immunocompetent elderly subjects with a live attenuated Oka strain of varicella zoster virus: a randomized, controlled, dose-response trial. Vaccine. 2000;18:1700-1706. 
37. Oxman MN, Levin MJ, Johnson GR, et al. A Vaccine to prevent Herpes Zoster and Postherpetic Neuralgia in older adult. $N$ Engl J Med. 2005;352:2271-84.

38. Schmader KE, Levin MJ, Gnann JW Jr, et al. Efficacy, safety, and tolerability of herpes zoster vaccine in person aged 50-59 years. Clin Infect Dis. 2012;54(7):922-928.

39. Breuer J. Vaccination to prevent varicella and shingles. J Clin Pathol. 2001;54:743-747.

40. Levin MJ, Smith JG, Kaufhold RM, et al. Decline in varicella-zoster virus (VZV)-specific cell-mediated immunity with increasing age and boosting with a high-dose VZV vaccine. J Infect Dis. 2003;188: 1336-1344.

41. Schmader KE, Oxman MN, Levin MJ, et al. Persistence of the efficacy of zoster vaccine in the shingles prevention study and the short-term persistence substudy. Clin Infect Dis. 2012;55:1320-1328.

42. Morrison VA, Johnson GR, Schmader KE, et al. Long-term persistence of zoster vaccine efficacy. Clin Infect Dis. 2015;60(6):900-909.

43. Tseng HF, Smith N, Harpaz R, Bialek SR, Sy LS, Jacobsen SJ. Herpes zoster vaccine in older adults and the risk of subsequent herpes zoster disease. JAMA. 2011;305:160-166.

44. Zhang J, Xie F, Delzell E, et al. Association between vaccination for herpes zoster and risk of herpes zoster infection among older patients with selected immune-mediated diseases. JAMA. 2012;308(1):43-49.

45. Gagliardi AMZ, Gomez Liva BN, Torloni MR, Soares BGO. Vaccines for preventing herpes zoster in older adults [review]. Cochrane Database Syst Rev. 2012;10:CD008858.

46. Diez-Domingo J, Weinke T, Garcia de Lomas J, et al. Comparison of intramuscular and subcutaneous administration of a herpes zoster live-attenuated vaccine in adults aged $>50$ years: a randomised noninferiority clinical trial. Vaccine. 2015;33(6):789-795.

47. European Medicines Agency. Zostavax (shingles [herpes zoster] vaccine [live]): EU summary of product characteristics; 2015. Available from: http://www.ema.europa.eu/docs/en_GB/document_library/ EPAR_-_Summary_for_the_public/human/000674/WC500053457. pdf.
48. Lu PJ, Euler GL, Jumaan AO, Harpaz R. Herpes zoster vaccination among adults aged 60 years or older in the United States, 2007: uptake of the first new vaccine to target seniors. Vaccine 2009;27(6):882-887.

49. National Center for Health Statistics (NCHS). Health, United States; 2005. Available from: http://www.cdc.gov/nchs/data/hus/hus05. pdf\#088.

50. Hinman AR, Orenstein WA. Adult immunization: what can we learn from the childhood immunization program? Clin Infect Dis. 2007;44:1532-1535.

51. Public Health England. Herpes zoster (shingles) immunisation programme 2013/14: cumulative coverage data (provisional) for England to end-April 2014. Health Protection Report. 8(21), May 30, 2014.

52. Ministere des affaires sociales, de la santé et des droit des femmes. Arrêté du 5 juin 2015 modifiant la liste des spécialités pharmaceutiques remboursables aux assurés sociaux. Journal Officiel de la Republique Francaise. 2015 n.132 Available from: http://www.legifrance.gouv.fr/ eli/arrete/2015/6/5/AFSS1512658A/jo/texte.

53. Van Epps P, Schmader KE, Canaday DH. Herpes zoster vaccination: controversies and common clinical questions. Gerontology. Epub July 16, 2015.

54. Williams WW, Lu PJ, O'Halloran A, et al; Centers for Disease Control and Prevention (CDC). Vaccination coverage among adults, excluding influenza vaccination - United Sates, 2013. MMWR. 2015;64(4): 95-102.

55. Teeter BS, Garza KB, Stevenson TL, Williamson MA, Zeek ML, Westrick SC. Factors associated with herpes zoster vaccination status and acceptance of vaccine recommendation in community pharmacies. Vaccine. 2014;32:5749-5754.
Patient Intelligence

\section{Publish your work in this journal}

Patient Intelligence is an international, peer-reviewed, open access journal that characterizes and measures the central role of patient behavior and intention in optimizing healthcare management in all areas of disease and complaint types. An improved understanding of patient intelligence coupled with predictive analysis helps an organization contribute more effectively to achieving better outcomes.

\section{Dovepress}

The journal is characterized by the rapid reporting of reviews, original research, methodologies, analytics, modeling, clinical studies and patient surveys across all disease areas. The manuscript management system is completely online and includes a very quick and fair peer-review system. Visit http://www.dovepress.com/ testimonials.php to read real quotes from published authors. 